\title{
Verification of re-use compatibility: the case of the Church of San Salvatore in Ortigia
}

\author{
S. De Medici \& C. Senia \\ Department of "Analisi, Rappresentazione e Progetto nelle Aree del \\ Mediterraneo" (DARP), Faculty of Architecture of Syracuse, \\ University of Catania, Italy
}

\begin{abstract}
The method of verification of re-use compatibility proposed has a double objective: to guarantee the conservation of the identity of the building, while preserving its configurative and material qualities; and to satisfy the requirements presented by its new use. The case study selected is the Church of San Salvatore on the island of Ortigia, which is the historical centre of the Sicilian city of Syracuse. Such a building has been profoundly changed by the variations in its use allocations undergone over the course of time. Following the use variation, the building underwent important structural modifications.

This research identified specific verification procedures of re-use compatibility, with the objective of checking that the transformations required by the variation in the use allotment are compatible with the constraints imposed by the existing building system and with the performances that the system provides. In particular, the use of new technologies is directed towards ensuring the conservation of the values expressed by the original form of the building and by its successive transformations and, at the same time, guaranteeing the reversibility of the interventions required by the new use.
\end{abstract}

Keywords: re-use, verification of compatibility, building system, settlement demand, constraints to the transformation.

\section{Introduction}

Re-use represents, in many cases, a strategy for conserving buildings in disuse or buildings that are about to enter into a state of disuse in an effective way, reconciling the demands of economic and social sustainability with those of 
conservation. In fact, variation in the use allocation guarantees continuity in the use of the heritage building, ensuring the prolongation of its usable life cycle [1].

In recent years numerous re-use interventions have involved a consistent quota of Italian heritage buildings. However, the absence of instruments and methodologies for the performing of compatibility checks between building constructions and new functions can cause the loss of identity, deeply modifying the structural characteristics of the properties and erasing the traces of the material culture to which these buildings are a testimony. Heritage buildings, on the contrary, must be considered as a resource to be valued and protected, through re-use interventions that do not cause the loss of the values that these buildings must continue to transmit. The need to define a method aimed at the control of the building intervention choices becomes paramount, in order to guarantee both the conservation and the use of the building, while at the same time respecting the values that the community recognizes in that building. The re-use intervention choices, consequently, must be founded on the search for a balance between conservation and transformation, accepting the fact that the heritage building is both an object endowed with multiple values (historical, artistic, symbolic, memorial, social, economic, etc.), and a resource to be reused. It is therefore necessary to verify whether or not the transformations, which the re-use action requires in order to satisfy the new use requirements, are compatible with the constraints imposed by the building, constraints deriving from the necessity of guaranteeing the protection of its values [2].

The present study considers the theme of the re-use of places of religious worship in disuse that, over time, have been the object of transformation interventions which allowed them to take on new functions. The introduction of new activities into places of religious worship - strongly characterized by large, undivided, internal spaces, whose configuration on the one hand generates high volumes of space but on the other hand provides a reduced amount of useable surfaces - requires, in many cases, transformative interventions aimed at increasing the surfaces to be allotted to the new functions and at guaranteeing the separation between the activities. This includes transformations to the building that can, if not carefully watched over, compromise the conservation of its cultural values.

\section{The case study: the Church of San Salvatore in Ortigia}

The object of the proposed research study is the Church of San Salvatore on the island of Ortigia, which is the historical centre of the Sicilian city of Syracuse (fig. 1). The church was built in 1652 in a small dead-end street leading off of Workmen's Street (via delle Maestranze), the decumanus maximus of the original city plan from the Roman Age of the ancient quarter of Ortigia [3].

The building, closed to religious worship in 1924, has been the object of a succession of changes in the use allocations relative to production activities: first it was a furniture factory, subsequently a centre for the production of wallpaper and, recently, a printing house. The building entered into its final state of disuse in the first years of the 21 st century. 


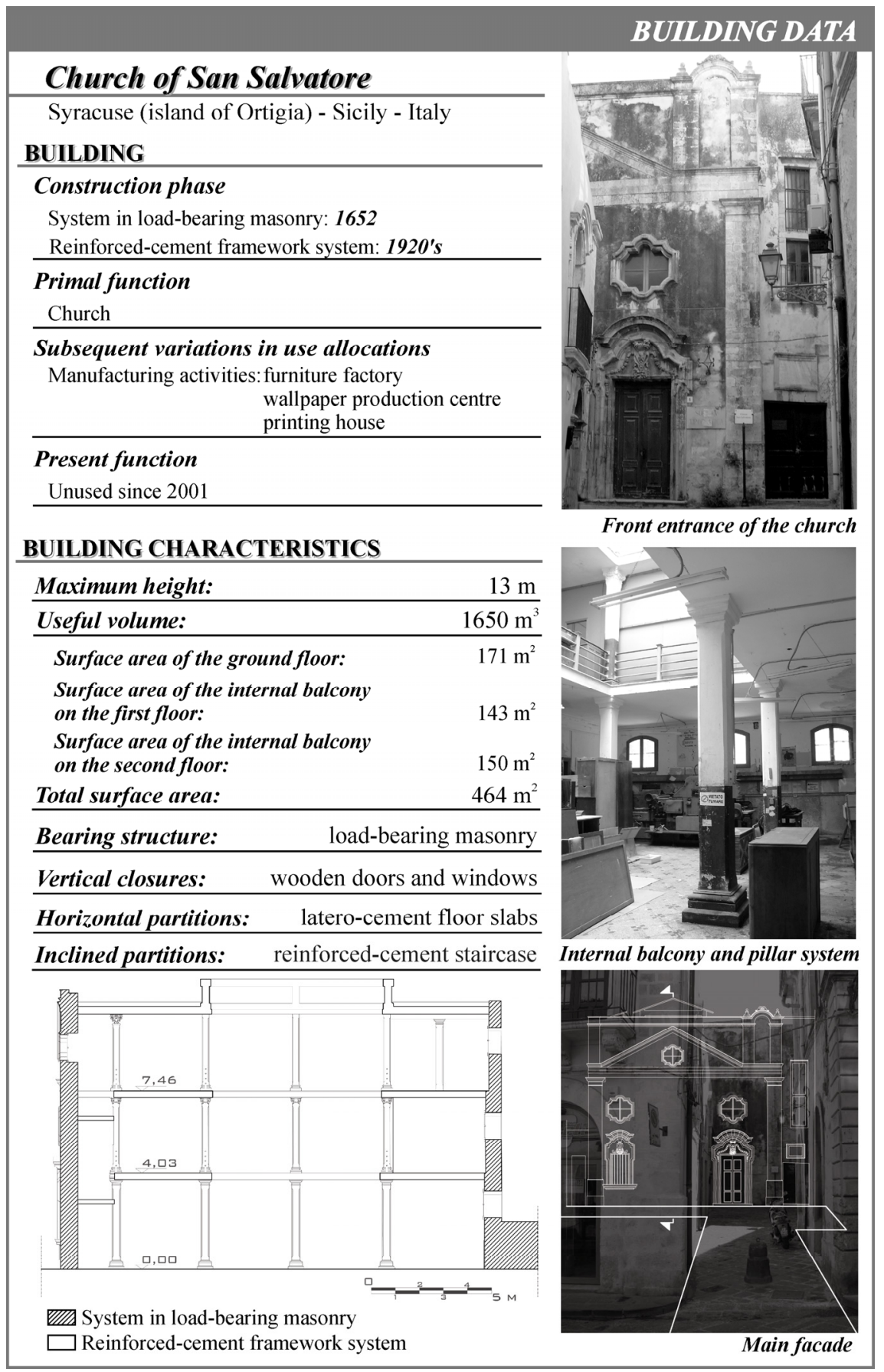

Figure 1: Identification file. 
The church was originally conceived according to a solid system in loadbearing masonry with a single nave. The transformations of the 1920 s caused the complete destruction of the decorative work and of the baroque finishes of the original building's internal space, exclusively conserving the wall casing and the decorations of the northern facade. The variation in the use allocation required the realization of a structure with a framework in reinforced cement, formed by three rows of pillars supporting the latero-cement internal balconies. These balconies, which face inwards along the full height of the nave, are vertically served by a staircase in reinforced cement, placed on the short side of the building. The vertical tripartition of the internal balcony system required, in order to ensure an increase in the natural light, the substitution of the original roofing. This was realized with the addition of a flat latero-cement floor slab with a central skylight, placed in correspondence with the internal space at the top of the building. Such an intervention shows how the building, over the course of time, took on multiple meanings, which add to its aesthetic and historical value, as an example of baroque architecture (fig. 2).

The current configuration of the church, in fact, documents the introduction of building systems with a framework in reinforced cement, that, in the early years of the 1900's, were used not only for the realization of autonomous structures, but also for transformation interventions of traditional buildings in load-bearing masonry. The characteristics of this structure from the 1900's testify to the influences of the Syracuse School of Art [4], noticeable in the decorative work of the pillars whose capitals give an account of, from the ground floor to the second level, the sequence of the classic orders of architecture (Doric, Ionic and Corinthian) (fig. 3). Moreover, the dividing of the internal space into multiple levels highlights the changing of the activities introduced onto the island of Ortigia in the last century, providing evidence of the economic and social development of the early 1900's, which gave rise to the installation of new forms of production in the historical centre.

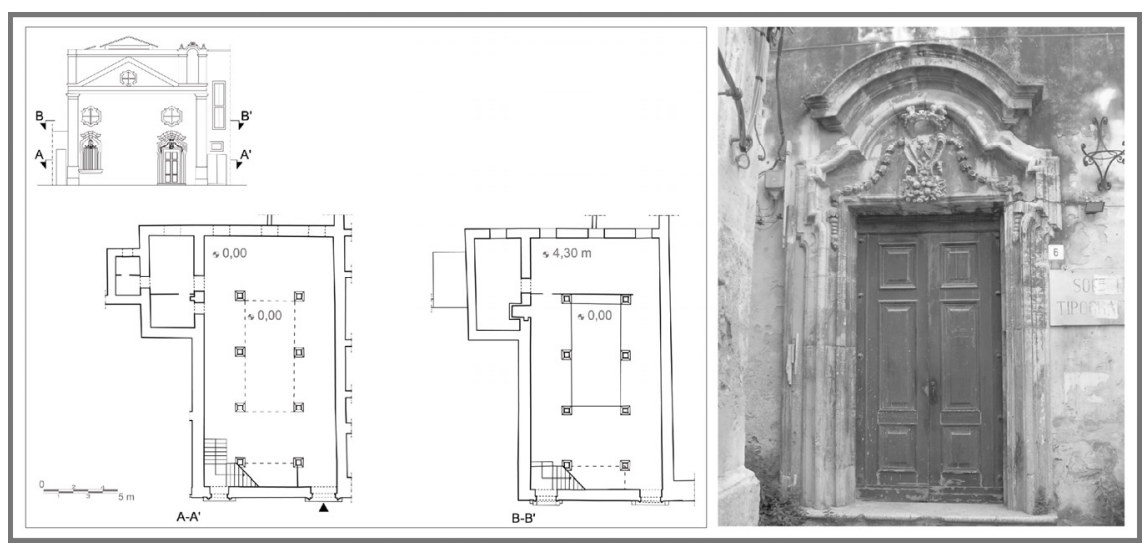

Figure 2: Main facade, ground floor, first floor and baroque decorative work. 


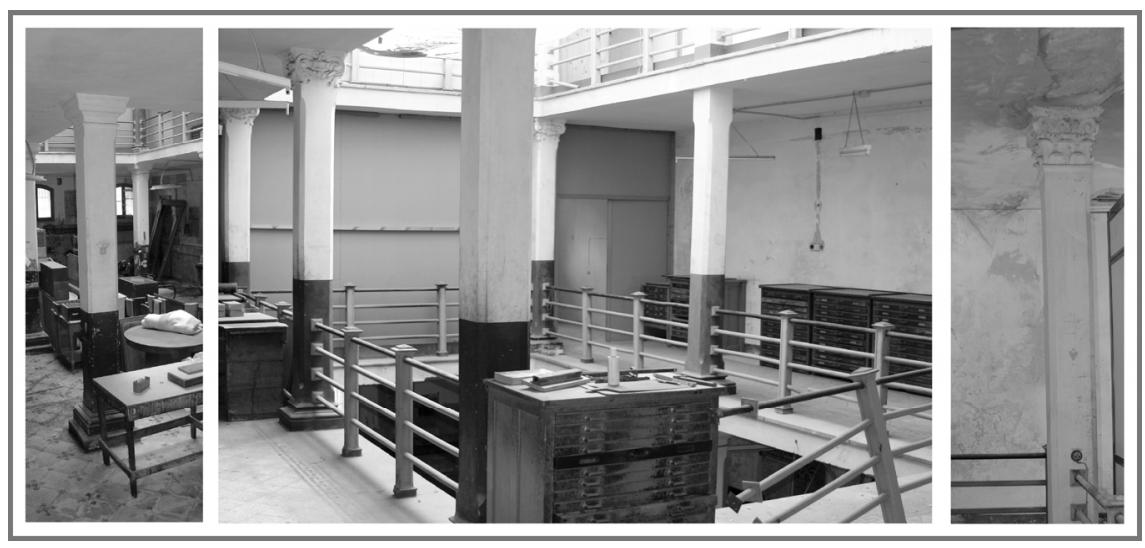

Figure 3: Reinforced-cement framework system, decorative work.

\section{Methodology}

The proposed methodology allows for the identification of new use allocations able to ensure both the conservation of the property and of the values that it expresses, and its promotion in relation to the development dynamics of the area, through a process of compatibility assessment (fig. 4).

The choice of new functions has the objective of defining, in line with a policy of sustainable development, new equilibriums for the settlement system of which the building is a part, bringing about positive repercussions on the physical, social and economic sub-systems that constitute it. The assessment of the social and economic context must be aimed at guiding the choices to be made about the physical structure, guaranteeing the intervention's compatibility with the characteristic features of the complete settlement system. This requires, in the first phase, the acquisition of information necessary both for gaining knowledge of the building, and for the identification of the use tendencies of the local urban system [5]. In fact, the re-use compatibility check is founded on the comparison between the performances that the building is able to offer and the requirements called for by the use allocations taken into consideration. The latter must be selected in relation to the settlement demand observed in the area. The assessment of the level of suitability of the performances guaranteed by the building with respect to the use requirements of the new activities to be set up allows for the identification of the performances that need to be increased or introduced with the re-use intervention [6]. The analysis of the building must guarantee, furthermore, the identification of the values that it expresses: in relation to such values it is then possible to define a system of constraints to the transformation, to be used as a guide in order to steer the choices of the intervention.

Starting with such information, the re-use intervention must search out a new equilibrium in the building system, balancing the conservation actions with the transformational ones. 


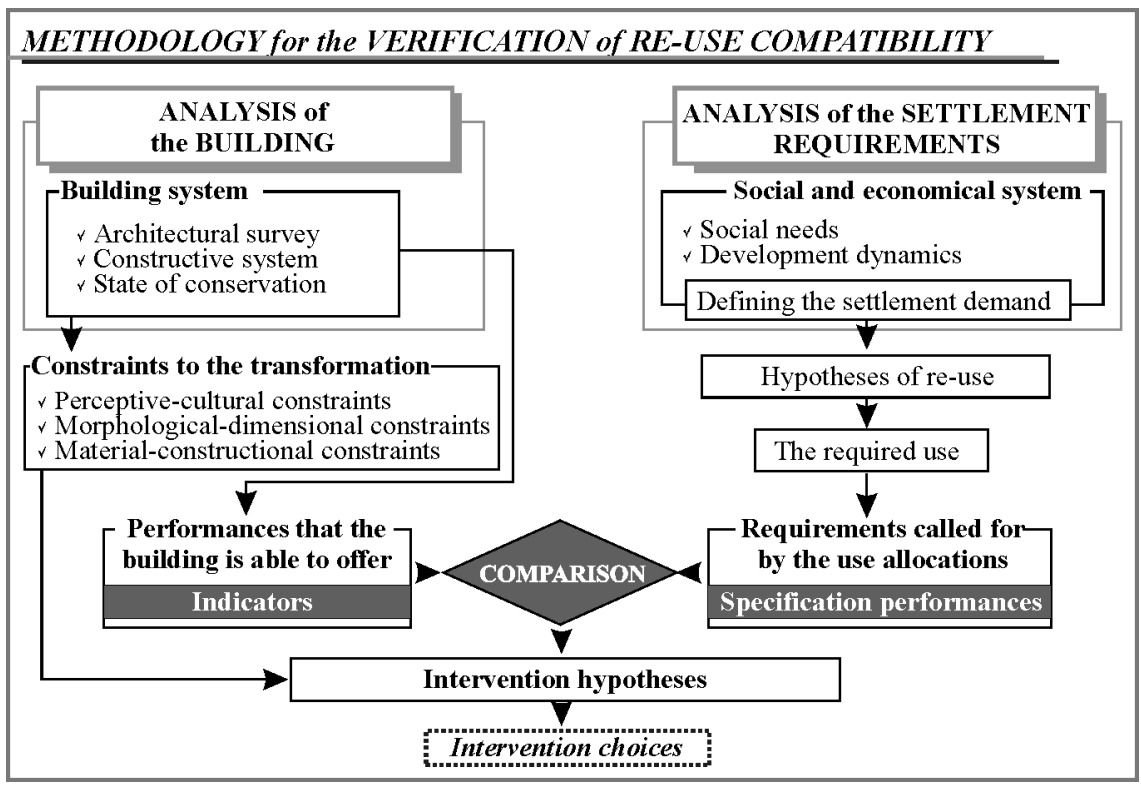

Figure 4: $\quad$ Methodological diagram of the study.

The result of the comparison between performances and requirements allows for the hypothesizing of some interventions that are then assessed with respect to the constraints presented by the building. Among these interventions those compatible with the constraints to the transformation are chosen.

\subsection{Analysis of the Church of San Salvatore in Ortigia}

This study begins with the knowledge that a building is a sum of inter-related elements, which take on an added value given their role as parts of a system [7]. In particular, the building in question is examined as a system of elevated complexity, being composed of heterogeneous elements, the links of which have varied over the course of time. The present configuration is the result of the integration of two building systems, whose overlapping has brought about both variations in the performances (containability, the ability to move throughout the church, furnishability, visibility, etc.), and alterations in the recognizable values (historical, aesthetic, psychological, constructional) of the building.

The characteristic features of the building led to the elaboration of three types of inquiries: the architectural survey, the analysis of the constructive system and the analysis of the state of conservation.

The architectural survey allowed for the graphic restitution of the complexity of the system and for the understanding of the dimensional relations among its parts. The analysis of the constructive system was conducted through the study of the building's technical elements, of their behaviour in use and of the relationships that exist between them, investigating, in particular, the connections between the load-bearing masonry system and the reinforced-cement 
framework system (fig. 5). The analysis of the building's state of conservation highlighted, in particular, the current conditions of equilibrium of the complex building system. This was accomplished through the study of the cracks in the church and through a mapping of the deterioration aimed at underlining the presence of alterations caused by the relations between the components of the original building organism and those of the framework structure.

Such analyses led to the definition of the sum of the performances guaranteed by the building and of the values that it is able to communicate today. This allowed for the establishment of the constraints to the transformation, conditions to be respected in order that the intervention choices not compromise the system of values expressed by the building. The constraints identified were classified according to the following categories:

- perceptive-cultural constraints, determined by the attribution to the building of values ascribable: to the constancy of the relationship of awareness between the user and the building; to the historical values documented by the variation in the use allocations that followed each other over the course of time; to the stylistic and artistic canons with which the technical elements are realized. Out of respect for such a category of constraints, the intervention must adhere to the following criteria: recognisability of the transformations, compatibility of the transformations, respect for the collective memory of the community, acceptability of the transformations, conservation of the pre-existing appearance, conservation of the aesthetic connections with the context, compatibility with the environmental tendencies;

- morphological-dimensional constraints, determined by the characteristics of geometric and stereometric configuration of the spaces and of the relations that these spaces have among themselves. Out of respect for such a category of constraints, the intervention must adhere to the following criteria: protection of forms, dimensions and proportions of the building and of its parts;

- material-constructional constraints, determined by the respect of the behaviour of the materials and of the building techniques. Out of respect for such a category of constraints, the intervention must adhere to the following criteria: conservation of the material, respect for the building system, the possibility of understanding the pre-existing system, reversibility of the transformations, and durability of the transformations.

\subsection{Analysis of the settlement requirements}

The choice of a new use allocation requires the survey of the settlement requirements of the area. Such a survey, in the case of the Church of San Salvatore, expanded upon the current development dynamics of the context and the emerging use demands. In order to guarantee the effectiveness of the re-use intervention, the new function must, at the same time, ensure both the economic sustainability of the intervention and satisfy the social demands of the community. The survey methodology adopted is aimed at the realization of a bottom-up process, which foresees the direct involvement of the local community in the intervention choices. Such participation is a strategic element 


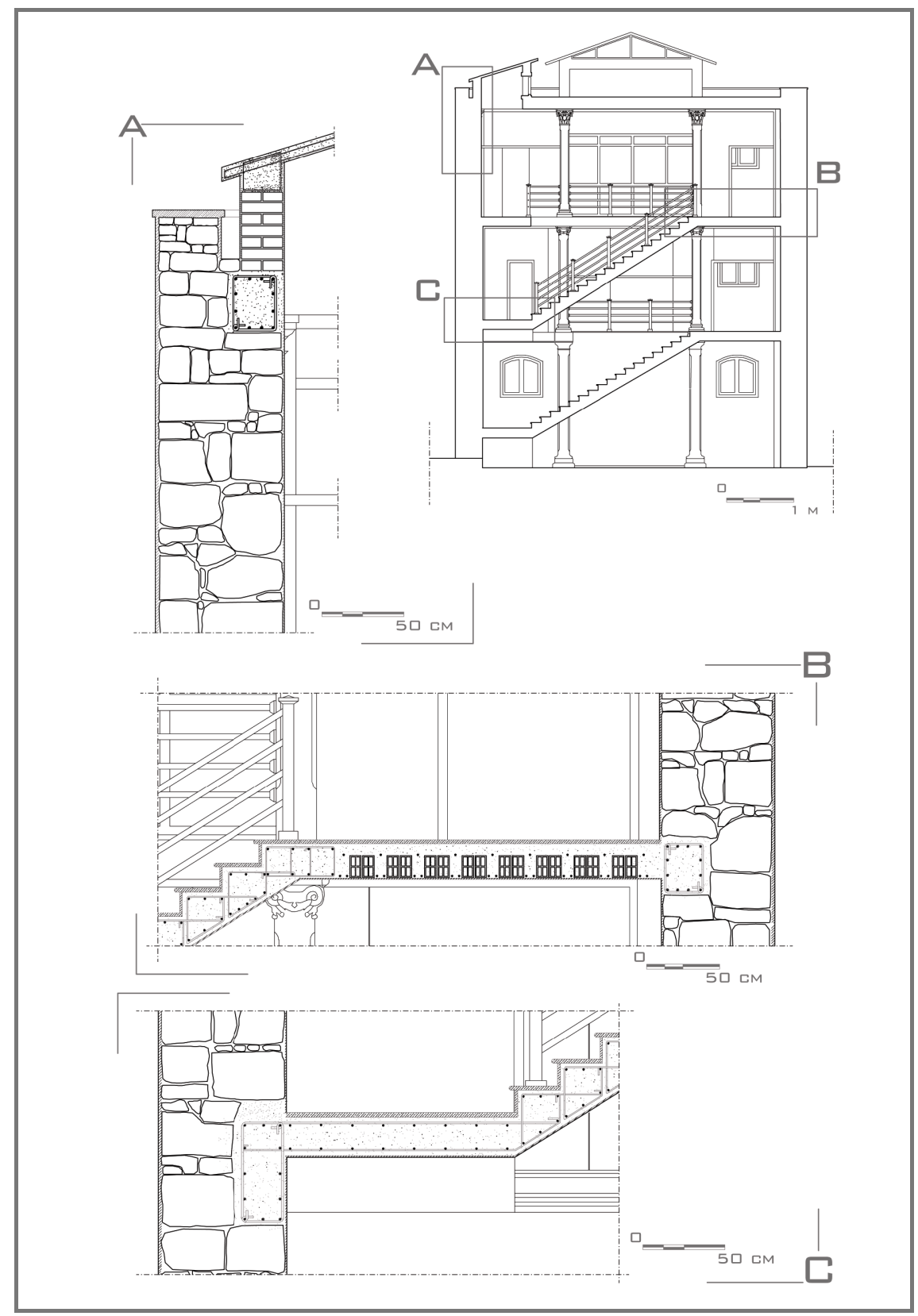

Figure 5: Connections between the load-bearing masonry system and the reinforced-cement framework system. 
for favouring the success of the intervention, promoting the sharing of re-use choices by the social groups present in the territory.

The first phase of defining the settlement demand was conducted starting with a preliminary survey of the laws dictated by the urban instruments in force in the local area, of the activities present in the urban area, established on a statistical basis, and of the use allocations of the zone. Subsequently, a campaign of interviews directed at a sample of users, representative of the social groups interested in the intervention, was conducted. The sample of users was subdivided into three categories: residents of the provincial territory (users that, though not frequently entering into direct interaction with the building, still prove to be interested in its re-use), residents of the historical centre (users that interact on a daily basis with the building), and privileged witnesses (representatives of local administrations and associations, that express the requests of direct and potential groups of users). For each category a questionnaire with open-ended questions was developed. These questions were divided into three parts, relative to the identity of the location, to the behaviour of the users and to the use of the location by the users, and to the proposals for the re-use of the building.

The analysis of the settlement demand guided the choice towards a category of use allocations of an artistic-artisanal type, which registered the greatest consensus from the local community.

The second phase in the selection of the new function required the development of an ulterior questionnaire, directed exclusively at potential direct users, with the aim of identifying, within the domain of the category of artisticartisanal use allocations, which activities to install in the building. The result of the survey highlighted the absence of an exhibition space for the promotion of local craft products. Furthermore, the suitability of such an activity with the touristic tendency of the urban area was confirmed. The exhibition space is able to satisfy the economic sustainability of the intervention: the new use allocation constitutes an opportunity for local artisans to increase the sale of their products. These local artisans expressed, accordingly, their willingness to invest in the management of the new function, in order to guarantee the upkeep of the building.

Having identified the activities that characterize the use allocation of exhibition space, the use requirements were defined, according to the laws dictated by mandatory regulations and the advice for the Classes of Requirement in terms of Security, Usability, Well-being and Management. The analysis of the use requirements led to the identification of ranges within which the levels of performance guaranteed by the building are considered to be satisfactory.

\subsection{Re-use compatibility check}

With the aim of verifying the re-use compatibility, a grid was prepared, comparing the performances of the technical elements that compose the building system with the requirements that are called for by the new function. Such a grid allows for the verification of the suitability of the performance levels offered by the building with respect to those required by the new use allocation. The 
comparisons with a negative result require intervention hypotheses able to increase the performance levels or to introduce new performances. Such hypotheses must be examined, in order to verify their compatibility with the transformational constraints previously identified. It is only the hypotheses compatible with the constraint categories that can be taken on as intervention choices.

The intervention hypotheses formulated for the Church of San Salvatore are directed at increasing, in particular, the performances of use flexibility, furnishability and adaptability of the spaces, the ability to move throughout the church, and control the natural light flow, pursuing, in addition, the objective of guaranteeing the reversibility of the interventions required by the new use allocation. The objects to be exhibited can vary in dimensions and characteristics: this requires variable configurations of the internal space, in order to allow for different displays. The constraint, determined by the necessity of conserving the recognisability of the successive transformations undergone by the building, directs the choice towards a system of removable floor slabs and balustrades, in order to increase, when necessary, the usable surface area, transforming the internal side-balconies of the structure from the 1900's into a continuous level. Such a solution allows for the modulation of the exhibition surface area according to demand, integrating the horizontal partitions. The substitution of the existing balustrades with new removable devices allows for, when putting the temporary floor slabs into use, their removal and their possible substitution with exhibition panels and shelves. The intervention choices relative to the floor slabs and to the balustrades boost the flexibility in terms of use, the furnishability, the adaptability of the spaces, and the ability to move throughout the church. The increase in this last performance, moreover, requires the installation of an elevator, that, in order to not alter the internal spaciousness of the building system, can be located in an existing service room, adjacent to the main room. The use allocation of exhibition space requires, furthermore, the improvement of the conditions related to visibility: this makes the partial transformation of the roofing from the 1900's necessary, roofing equipped with a central skylight, in order to integrate the existing external fixtures of the skylight into systems that control the natural light flow, in order to allow for the partial or total darkening of the exhibition space (fig. 6).

\section{Conclusion}

The choice of new use allocations for buildings in a state of disuse is an occasion both for the conservation of existing heritage buildings, understood as resources, and for the development of settlement systems. Re-use, therefore, constitutes an instrument for the promotion of heritage buildings on an urban and territorial scale, bringing about repercussions on the socio-economic conditions of the context. However, when the building to be re-used is endowed with aesthetic, historical, psychological, and constructional values and, in particular, testifies to social, economic and cultural evolution through the traces left behind by multiple periods of re-use, the re-use intervention also becomes an occasion for preserving and narrating the history of the local community. 


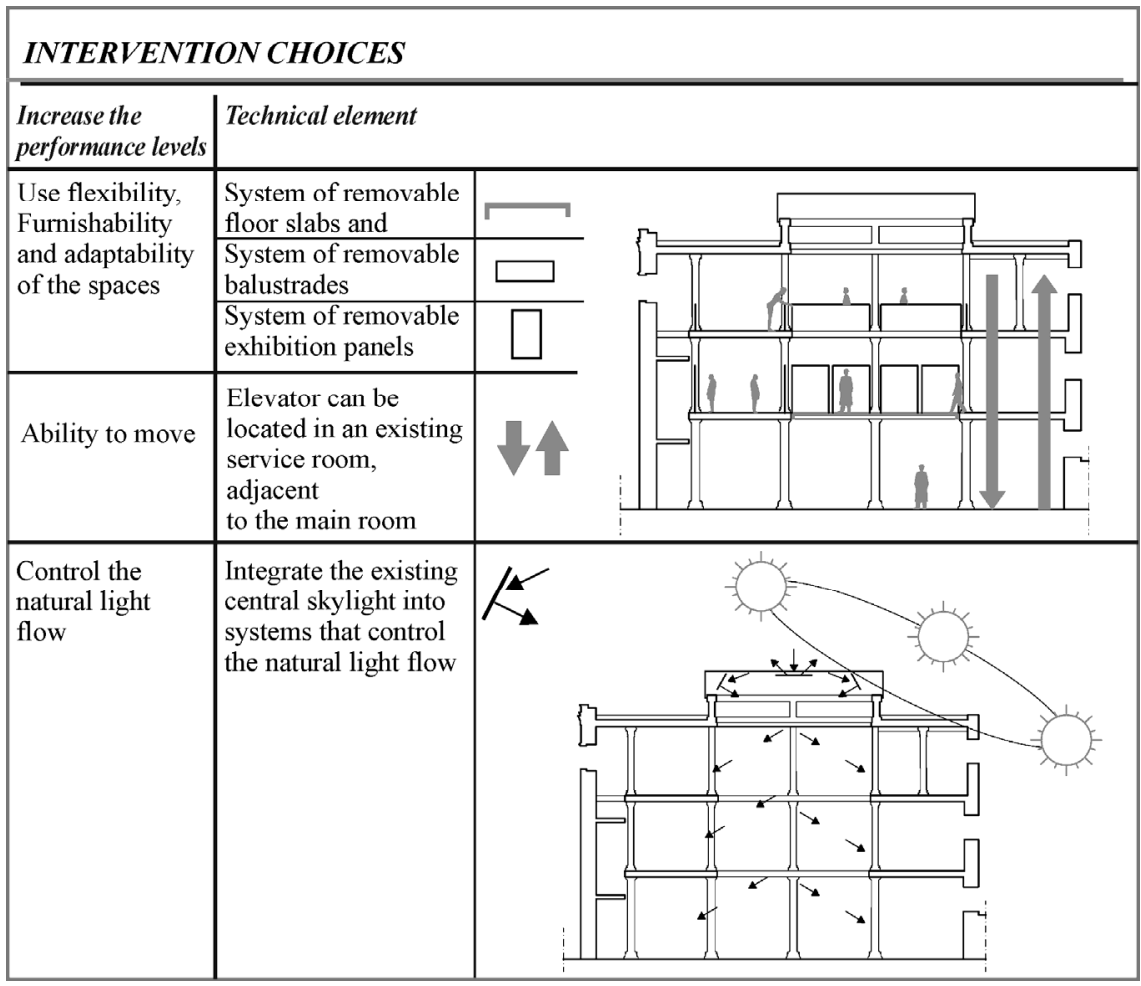

Figure 6: Choices of the intervention.

The compatibility check of the new activities to be set up with the preexisting characteristics of the building represents the necessary instrument for guaranteeing the continuity of the narration, controlling the results of the transformational and modification interventions to be carried out. Through the application of such a method it is possible to analyze each hypothesis of modification for the building to the new function and compare it with the system of constraints to the transformation, which derive from the values recognized in the building. This allows for the quality control of the results of each transformational action, ensuring the constancy of the values that the building is able to transmit to the community.

\section{Acknowledgements}

The authors wish to thank arch. Alessandra Carasi for providing technical drawings and photographs of the Church of San Salvatore in Ortigia. Stefania De Medici is the author of sections 3 and 3.1. Carla Senia is the author of sections 2, 3.2 and 3.3. 
532 Structural Studies, Repairs and Maintenance of Heritage Architecture XI

\section{References}

[1] Pinto, M., Il riuso edilizio. Procedure, metodi ed esperienze, Utet Libreria: Torino, 2004.

[2] Cantone, F., De Medici, S. \& Senia, C., Reuse strategies for Sicilian architecture: the case of the "Masseria Maucini". Proceedings of the CIB W70 International Symposium on the "Changing user demands on buildings. Needs for lifecycle planning and management”, eds. T.I. Haugen, A. Moum \& J. Bröchner, The Norvegian University of Science and Technology (NTNU): Trondheim, pp. 85-93, 2006.

[3] Acerra, L., Architettura religiosa in Ortigia. Viaggio nella città invisibile, Ediprint: Siracusa, 1995.

[4] Carratore, A., La regia scuola d'arte applicata all'industria di Siracusa, Felice Le Monier: Firenze, 1941.

[5] Caterina, G., Pinto, M.R., Fabbricatti, K., Oppido, S., De Medici, S., De Toro, P. \& Bianchi, A., Reusing and Managing the "Real Albergo de' Poveri" of Naples: Evaluation and Re-Design for Improved Efficiency. Proceedings of the CIB W70 International Symposium on the "Facilities, Management and Maintenance”, eds. D.T. Shiem-Shin, K. Johnes \& J. Hinks, The Hong Kong Polytechnic University: Hong Kong, pp. 129-139, 2004.

[6] De Medici, S., Definizione dei requisiti del progetto di riuso. Il Real Albergo de' Poveri di Napoli. La conoscenza del costruito per una strategia di riuso, eds. G. Caterina \& P. De Joanna, Liguori Editor: Napoli, pp. 369-378, 2007.

[7] Ciribini, G., Tecnologia \& progetto. Argomenti di cultura tecnologica della progettazione, Celid: Torino, 1995. 